\title{
Correction to: Immunity, thought insertion, and the first-person concept
}

\author{
Michele Palmira ${ }^{1,2}$ (D)
}

Published online: 20 April 2020

(c) Springer Nature B.V. 2020

\section{Correction to: Philos Stud https://doi.org/10.1007/s11098-019-01411-z}

In the original publication of the article, the funding information was inadvertently missed out. The information is provided in this Correction.

Funding Work in this article has received funding from the European Union's Horizon 2020 Research and Innovation programme (H2020-MSCA-ITN-2015-675415); the Ministerio de Ciencia, Innovación y Universidades/Agencia Estatal de Investigación/Fondo Europeo de Desarrollo Regional, Unión Europea (RTI2018-096225-J-100); the Agència de Gestió d'Ajuts Universitaris i de Recerca (2016BP-00132); the Ministerio de Economía, Industria y Competitividad, Gobierno de España (FFI2016-80588-R).

Publisher's Note Springer Nature remains neutral with regard to jurisdictional claims in published maps and institutional affiliations.

The original article can be found online at https://doi.org/10.1007/s11098-019-01411-z.

Michele Palmira

michelepalmira@gmail.com

1 Department of Philosophy, University of Barcelona, c/ Montalegre 6-8, office \#4067, 08001 Barcelona, Spain

2 BIAP/LOGOS Research Group, University of Barcelona, Barcelona, Spain 